\title{
MEMÓRIAS DA GUERRILHA: CONSTRUÇÃO E TRANSFORMAÇÃO
} GUERRILLA'S MEMORIES: CONSTRUCTION AND TRANSFORMATION

\author{
Domenico Uhng Hur \\ Universidade Federal de Goiás, Goiânia, Brasil
}

\begin{abstract}
RESUMO
Neste artigo discutimos a reconstrução do passado a partir de relato de um ex-guerrilheiro urbano que lutou contra a ditadura militar brasileira, através da concepção da memória como construção e ação social. Para tanto, entrevistamos o ex-guerrilheiro de codinome Jamil Rodrigues, conhecido por ter elaborado as "Teses do Jamil", documento da Vanguarda Popular Revolucionária - VPR, reconhecido como a expressão máxima da estratégia militarista nas práticas da esquerda armada brasileira. Constatamos que houve um processo de transformação; Jamil faz uma interpretação bastante diferenciada de suas antigas teses, em que atenua os aspectos militaristas da luta armada. A sua memória é interessada: seleciona e intensifica as passagens que convergem com seu posicionamento político presente. Concluímos que a construção da memória aparece como produção do novo e está agenciada pelo presente, adotando uma plasticidade contingente ao lugar social que se ocupa na atualidade.
\end{abstract}

Palavras-chave: ditadura militar; guerrilha; Psicologia Política.

\begin{abstract}
In this article we discuss the reconstruction of the past from report of a former-guerrilla fighter who fought against the Brazilian military dictatorship, through the perspective of the memory as construction and social action. We interviewed the former-guerrilla fighter nicknamed Jamil Rodrigues, known for writing the "Jamil's thesis", document of Revolutionary Popular Vanguard, recognized as the maxim expression of militarist strategy in the practices of the Brazilian armed left. We noted a transformation's process; Jamil does a quite differentiated interpretation of his ancient thesis, reducing the militarist aspects of armed struggle. His memory is interested and it selects and intensifies the passages that converge with his present political position. We conclude that the construction of memory appears as production of the new and is assembled by the present, adopting a contingent plasticity to the social place that is occupied in the present.
\end{abstract}

Keywords: military dictatorship; guerrilla; Political Psychology.

No ano de 2012 foi instituída a Comissão Nacional da Verdade no Brasil. Tal como nos outros países da América Latina, a Comissão da Verdade tem como função apurar as violações de direitos humanos e violência do Estado exercidas em períodos de exceção; no caso do Brasil, entre os anos de 1946 e 1988. A criação da Comissão da Verdade traz à tona a ideia de que pode haver outras verdades encobertas pela versão da História oficial de Estado; histórias minoritárias que podem alterar nossa própria compreensão sobre a constituição de nossa nação e do Estado. A emergência de outros discursos sobre a história traz um conflito denominado de guerra das memórias (Dobles, 2009).

Em nosso tema de pesquisa, que abarca o período da ditadura militar brasileira, esse conflito aparece intensamente, havendo grande tensão no processo. Inicialmente tínhamos a "antiga" História oficial, em que os guerrilheiros eram chamados de terroristas e as Forças Armadas de defensores da pátria. Os participantes da esquerda armada eram criminalizados e os militares heroicizados; avenidas e estradas recebiam o nome de oficiais militares da ditadura, enquanto muitos assassinados e desaparecidos políticos da esquerda amargavam o esquecimento, enterrados como indigentes, como, por exemplo, nas ossadas encontradas no ano de 1990 na vala de Perus/SP. Mesmo nas disciplinas de História do Brasil, no Ensino Básico, os presidentes militares da época da ditadura raramente são retratados como regentes de um período marcado por um estado de exceção, infrações às leis, torturas, assassinatos e graves crimes contra os direitos humanos, e sim como presidentes "neutros" que operaram o mítico 
"Milagre Econômico" brasileiro. Ou seja, registrase, conserva-se e transmite-se uma história oficial mutilada, uma história velada e inventada, que é uma história de Estado, comprometida com o poder e que visou beneficiar os grupos dominantes que o ocupam e ocuparam; Merleau-Ponty (1991) a chamaria de a história dos vencedores. Este uso da história pelos vencedores está em conformidade com as afirmações de Elizabeth Jelin (2002), que diz tratar-se de atores sociais que lutam pelo poder e que buscam legitimar suas posições vinculando-as a ações "heroicas" do passado, “donde 'buenos' y 'malos' están claramente identificados" (p. 41). O filósofo Michel Foucault (1999) ressalta a importância de desenvolver uma "contra-história", que combata a história oficial de Estado e esteja implicada com o desvelamento do que foi intencionalmente omitido e distorcido.

Dessa forma, dando visibilidade a essa outra história, o objetivo deste artigo é discutir como se dá a construção da memória a partir de relato de um ex-guerrilheiro que foi considerado um dos principais defensores da estratégia militarista contra a ditadura militar. Visamos a analisar como ele reapresenta e constrói seu passado através do olhar do presente, partindo da concepção da memória como construção e ação social (Vázquez, 2001). Para tanto, escolhemos um caso emblemático: entrevistamos o exguerrilheiro de codinome Jamil Rodrigues, conhecido por ter elaborado as Teses do Jamil, documento da Vanguarda Popular Revolucionária - VPR. Esse documento é reconhecido como a expressão teórica máxima da estratégia militarista nas práticas da esquerda armada brasileira, o qual será comentado no terceiro tópico. Atualmente, Jamil é um renomado professor universitário e economista reconhecido internacionalmente.

\section{A memória como construção e ação social}

O historiador Andreas Huyssen afirma que os novos discursos sobre a memória surgiram na Europa para discutir e elaborar temas como o Holocausto e na América Latina "como consecuencia de la descolonización y de los nuevos movimientos sociales que buscaban historiografias alternativas y revisionistas" (2002, p. 14). Os relatos orais trazem um outro lado, uma outra versão da "história oficial", mais localizada, regional, micropolítica; uma história recheada com fatos cotidianos. Michel de Certeau ressalta que nessas narrações há "um saber dizer exatamente ajustado a seu objeto e, a este título, não mais o outro do saber, mas uma variante do discurso que sabe e uma autoridade em matéria de teoria"
(1994, p. 153). Thompson (1992) defende que a história oral é uma maneira de democratizar a História, em que as minorias excluídas, os não ouvidos, também têm seu direito de se expressarem e de constituírem história. De acordo com Bosi (2003), a memória oral constitui (mas não totaliza) o que se chama de História das Mentalidades, a História das sensibilidades. Tais perspectivas ressaltam o caráter construtor dos relatos, produzidos através dos trabalhos da memória. O psicólogo social espanhol Félix Vázquez (2001) desenvolve a faceta construtora da memória, ao afirmar que ela:

se construye en cada relación, pero cada relación es deudora de otras, simultáneas y precedentes, así como de la historia y la cultura de una sociedad. Hacer memoria no es proceder siguiendo una secuencia lineal de acontecimientos en el tiempo. La memoria evoluciona mediante rodeos y desviaciones, construyendo para el momento el relato y su temporalidad. (p. 125)

A memória não é algo que fica restrito aos museus, que fica guardado, estático, em depósitos e que apenas diz respeito ao passado; tem uma dinamicidade, um movimento de construção e reatualização, como se fosse um filme interativo que sempre (re)constrói suas cenas e sentidos, ao invés de um filme terminado ou uma foto tirada. Para Vázquez (2001), longe de a memória ter apenas uma função de arquivo e de recuperação de um passado, tem uma ação social de produzir discursos e realidades, de prover continuidade a um conjunto social, concepções sobre a sociedade e de ser um processo do presente que reconstrói o passado para a geração de futuro(s), entre outros fatores. A memória e o esquecimento sociais, que correspondem ao mesmo processo, "responden primordialmente más a intereses del presente que del propio pasado" (Vázquez, 2001, p. 29). Tal concepção, herdeira de concepções do construcionismo social e do pragmatismo, entende que a memória é uma reconstrução desde o presente que se atualiza através da linguagem e das práticas sociais; enfim, apreendese a memória como uma ação social, que vai além da mera representação e da recuperação e que é produtora concreta de relações e realidades. Compreende-a como pragmática, o que tira de si apenas seu caráter evocativo e representativo.

La realidad social es procesual: no se puede concebir como un resultado. El presente es un proceso en continua construcción y el pasado también. Entre ambos pivota la memoria que dota de continuidad la realidad social. Mediante la memoria se construyen y resignifican los acontecimientos. Sin embargo, la realidad social no se detiene en la construcción del pasado y del presente: se proyecta en el futuro. La memoria, como vínculo 
que provee de continuidad, permite la proyección en el futuro. (Vázquez, 2001, p.25)

Então, o que chama a atenção nesta abordagem é o fato de a construção da memória produzir tanto o presente quanto o passado. Desse modo, o trabalho da memória indubitavelmente constrói acontecimentos e realidades sociais, concepções de mundo e fatos, que são base e suporte para a geração de novos significados, sentidos e ações sociais. Fenômenos que não são estanques e são dotados de uma dinâmica, plasticidade e um movimento de autotransformação, ou o que Castoriadis (1982) chama de autoalteração e autoinstituição, ou seja, a memória é uma máquina performativa de produção de sentidos e realidades, estando em contínua variação e movimento que sempre pode conformar acontecimentos. $\mathrm{Na}$ construção da memória, o passado não é apresentado como determinante para construir o atual posicionamento, mas sim o inverso, o presente é que constrói e seleciona as formações do passado. O passado é invocado como justificativa para o atual posicionamento, ou seja, há uma modulação, uma plasticidade do passado, que é atualizado para referendar as escolhas e posicionamentos políticos do presente.

Los relatos testimoniales son "discurso" en este sentido porque tienen como condición un narrador implicado en los hechos, que no persigue una verdad exterior al momento en que ella se enuncia. Es inevitable la marca del presente sobre el acto de narrar el pasado, precisamente porque, en el discurso, el presente tiene una hegemonía reconocida como inevitable y los tiempos verbales del pasado no quedan libres de una "experiencia fenomenológica" del tiempo presente de la enunciación. "El presente dirige el pasado como un director de orquestra a sus músicos", escribió Italo Svevo. Y, como observaba Halbwachs, el pasado se distorsiona para introducirle coherencia. (Sarlo, 2005, pp.64-65)

“La memoria, como se ha dicho, 'coloniza' el pasado y lo organiza sobre la base de las concepciones y emociones del presente" (Sarlo, 2005, p. 92).

Outra contribuição singular de Vázquez ao estudo da memória, que a dota ainda mais de pragmatismo e produção, é quando liga a noção de imaginário social ao funcionamento da memória. Para ele, a construção da memória não se realiza apenas a partir do que foi, mas também a partir do que pode ser, do que se anseia, ao levar em conta também o que se pretende do futuro, o que se imagina para o futuro (Vázquez, 2001, p. 151), ou então o que Deleuze e Guattari (1996) chamam de devires. Assim, o imaginário social conjuga-se à memória dando-lhe um caráter instituinte e criador, provendo um espaço de abertura e indeterminação em que a memória é produtora de possibilidades, do futuro e de realidades ao portar a potência instituinte da imaginação. Então, o imaginário social é instância produtora de realidades, de devires, ao ligar-se ao dispositivo da memória.

Abordar a memória enquanto ação social e produção de novidade faz com que se abandone o modelo anamnésico da memória, pois esse lhe confere uma estaticidade, uma reversibilidade, como se houvesse apenas uma versão e a "ilusão determinista" da série passada sobre as séries futuras, como se o sujeito ficasse sempre capturado pelo seu agenciamento originário, ou a sua configuração vincular familiar fundante. Em nossa perspectiva, a memória não é restituição, e sim construção. Há um processo dinâmico de construção que constitui diferentes versões e resulta num intenso conflito de memórias, no intento de convertê-las em história. E as memórias da ditadura militar ainda estão em disputa, em que diversos atores sociais contrapõem-se à versão oficial de Estado, na tentativa de consolidação de outras versões.

\section{Guerra das memórias: a guerrilha e os militares}

Nas Ciências Sociais, Halbwachs (2004) é um dos pensadores de referência que se ateve à problemática da coletividade da memória, do compartilhamento da memória por um coletivo. Compreende a memória enquanto fenômeno de natureza social, dependente do relacionamento do indivíduo com grupos, seja com o grupo familiar, de trabalho, comunitário, isto é, dos laços sociais que constitui no decorrer de sua vivência. E é nessa articulação entre memória e sociedade que o autor cria o conceito de memória coletiva, que se distingue da História, pois articula o que do passado mantém-se vivo no presente, a partir de diversas formas. A memória é assim constituída e transmitida através de diversas materialidades, como por narrativas orais, livros, datas festivas, monumentos, filmes, produções artísticas etc., o que lhe confere seu caráter e perfil social, coletivo. Tal conceito referenciou inúmeras pesquisas sobre memória na Psicologia Social, como por exemplo o trabalho desenvolvido por Ansara (2008) sobre o conceito de memória política, que, grosso modo, é a conjunção dos conceitos de memória coletiva de Halbwachs e de consciência política de Sandoval (2001). Em relação às "memórias da ditadura", no Brasil temos uma polarização da memória coletiva que se refere à produção de dois grupos sociais: dos ex-guerrilheiros e dos militares que defendem o período da ditadura militar. 
Com a reabertura política desde o fim da década de setenta, ocorreu intensa publicação de memórias e de análises do período da ditadura militar por ex-guerrilheiros, tanto na forma de romances, de biografias, autobiografias como em livros acadêmicos. As primeiras publicações sobre a luta armada foram o romance Em câmera lenta do ex-militante da Ala Vermelha, Renato Tapajós (1977), que criou um texto de ficção sobre experiências vividas na luta armada, e o famoso livro $O$ que é isso, companheiro? do exdeputado federal do Partido Verde - PV, Fernando Gabeira (1979), cuja obra retrata alguns episódios de sua militância no MR-8 - Movimento Revolucionário Oito de Outubro - e o sequestro do embaixador norteamericano Charles Burke Elbrick. O livro de Gabeira atingiu grande visibilidade, sendo adaptado para o cinema em 1997 e, por mais que tenha sido criticado por ex-guerrilheiros, abriu espaço para outras obras memorialísticas, sejam biográficas ou autobiográficas, como os escritos do também político do PV Alfredo Sirkis (1980), do ex-militante do PCBR - Partido Comunista Brasileiro Revolucionário Álvaro Caldas (1981/2004), do ex-militante da VPR e atual liderança religiosa do Santo Daime Alex Polari (1982), do dominicano Frei Betto (1982), cuja obra Batismo de Sangue também foi adaptada ao cinema, e livros mais recentes, como das viagens à luta armada dos ex-militantes da Ação Libertadora Nacional (ALN), Carlos Eugênio Paz (1996, 1997), Ottoni Fernandes Jr. (2004) e Virgílio Gomes da Silva (Pimenta \& Teixeira, 2009), do ex-militante do Movimento Nacionalista Revolucionário (MNR) e do Movimento Armado Revolucionário (MAR), Flávio Tavares (1999), dos ex-militantes da VPR, Maria do Carmo Brito (Vianna, 2003), Celso Lungaretti (2004), Liszt Vieira (2008) e Pedro Lobo de Oliveira (Laque, 2010), entre muitos outros. Também há biografias que exaltam o lado heroico do Capitão Lamarca (José \& Miranda, 1980) e de Carlos Marighella (José, 1997) e sobre a história do ex-guerrilheiro do Araguaia e ex-deputado federal do Partido dos Trabalhadores - PT- José Genoíno (Coelho, 2007).

Desse modo, a história dos então considerados "terroristas", criminosos, inimigos da pátria, a história das "minorias", do "subterrâneo" veio à tona e adquiriu grande capilaridade na sociedade, que resultou em inúmeras adaptações ao cinema e em minisséries televisivas nas décadas de 1990 e 2000, paradoxalmente muitas capitaneadas pela Rede Globo, emissora aliada do regime militar. Então, com a ampliação da transmissão das memórias da ditadura, tivemos o que Reis Filho (1990) chama de um deslocamento de sentido, em que os participantes da luta armada passam a ter outra representação na sociedade, e os militares também. Há uma mudança de representações, em que os militares passam a ter a representação de "opressores", enquanto os guerrilheiros de "personagens heroicos e idealistas", os heróis dos "Anos Rebeldes". Outro exemplo é de que Che Guevara também não ocupa mais o lugar de "terrorista", de mandante de fuzilamentos, mas de revolucionário libertário e sonhador, do amor revolucionário, referência de milhões de jovens do mundo todo, que compram suas camisetas, boinas do modelo que usava e tatuam sua face em seus corpos: Che Guevara tornou-se um símbolo da revolução e transformação social.

Conscientes desse "deslocamento de sentido", os oficiais militares da época da ditadura também passaram à ofensiva e escreveram seus livros, suas memórias, na tentativa de propagar e consolidar a sua versão dos fatos, em que os guerrilheiros figuram como um perigo para a nação. Citamos o Coronel reformado Carlos Alberto Brilhante Ustra, ex-comandante do DOI-CODI-SP - Destacamento de Operações de Informações / Centro de Operações de Defesa Interna - , com os seus livros Rompendo o Silêncio (2003) e Verdade Sufocada (2006), e a colocação recente online do documento "Projeto Orvil", texto de quase mil páginas elaborado pelos militares no período da redemocratização brasileira sobre a tentativa de "tomada de poder" da esquerda durante o período pré e da ditadura militar, mas que na época não foi publicado "para evitar revanchismos", conforme as palavras do General Leônidas Gonçalves, Ministro do Exército no Governo Sarney. Outra mídia de opiniões de militares que enaltece o regime militar é o site do grupo "Terrorismo Nunca Mais" - TERNUMA, www.ternuma.com.br. Todas essas publicações qualificam as ações dos grupos guerrilheiros como terroristas e pretendem fortalecer a versão da história da ditadura militar, justificando a ação dos militares da época como defesa da segurança nacional contra o perigo comunista.

Vale citar, no que tange ao número de publicações sobre o período da ditadura, que os militares apresentam produção reduzida em relação aos grupos de esquerda: "Pode-se estimar que entre 1979 e 2000, para cada dez livros de memórias e biografias de oposicionistas, publicou-se apenas um relacionado com as lembranças ou a vida dos hierarcas da velha ordem" (Gaspari, 2002, p.37). Decerto a literatura produzida pelos militares, além de ser menos numerosa, atualmente não tem muita propagação e ressonância na sociedade brasileira, mas existe e está na luta no conflito de memórias, querendo afirmar sua versão dos fatos e da História. Pode-se entender então que a memória é interessada e 
implicada, em que "a produção de discursos e versões sobre o passado não é arbitrária nem casual, senão que se inscreve na trama de relações que produzem, reproduzem e alteram a sociedade" (Rovira \& Vázquez, 2004, p. 143, tradução nossa).

João Roberto Martins Filho (2003), ao discutir essa "guerra da memória", aborda algumas produções escritas de militantes de esquerda e militares. Para Martins Filho, uma visão hegemônica emergente e frequente dos textos dos militares das três forças se baseia no argumento de que "anistiar é zerar as contas e, portanto, esquecer" (p. 182), em que os militares, depois de promulgada a anistia às vítimas e aos agentes da violência de Estado da ditadura militar, preferem colocar uma "pedra" sobre o passado e construir o futuro. Provavelmente uma tática de esquecimento frente aos abusos contra o Estado democrático e os direitos humanos cometidos no passado, ou tentativa de obedecer cegamente o que a anistia quer traçar em relação aos crimes de guerra. Talvez seja essa uma das razões para que os militares tenham "retardado" o registro e transmissão de suas memórias em relação aos militantes de esquerda, em que suas publicações assumem uma posição de ataque sobre as versões dos ex-guerrilheiros e as ações de reparação a estes. Os militares tentaram rechaçar a anistia e promoção do Capitão Carlos Lamarca, considerado por eles como grande traidor das Forças Armadas, visto que desertou para ir à guerrilha armada, e recusam assumir a responsabilidade do Estado em relação aos crimes cometidos contra os mortos e desaparecidos políticos, após o decreto da Lei 9.140/95. Vale ressaltar que pouquíssimos agentes do Estado, militares ou civis, envolvidos com a repressão relatam claramente suas experiências. Alguns que o fazem são motivados pela culpa pelo exercício da violência, como o exdelegado do DOPS - Departamento de Ordem Política e Social - e atualmente pastor evangélico Cláudio Guerra (2012), que em livro recém-lançado contou os bastidores de muitos atos emblemáticos da violência de Estado em que participou.

Recentemente um editorial do Jornal Folha de São Paulo, intitulado "Limites a Chávez" (2009), entrou explicitamente na guerra de memórias denominando a ditadura militar brasileira de "ditabranda", com o intuito de diminuir a intensidade da violência do regime militar brasileiro ao comparar com outras ditaduras latino-americanas, que assassinaram mais pessoas. Portanto, como houve mais assassinatos em outras ditaduras na América Latina, a Folha de São Paulo utilizou esse dado para amenizar a violência do regime militar, transmitindo a ideia da ditadura brasileira como "branda".
Desse modo, entende-se que a "História Oficial" de hoje em dia não é a história oficial de outrora, a que os militares consolidaram; está em transição. Considera-se que essa mudança de perspectiva deriva da expressão dos movimentos sociais e de direitos humanos, dos intelectuais politicamente engajados e de gestões de governos que defenderam as políticas de direito à memória. Assim, a história das minorias sociais que combateram a ditadura passa a se autoinstituir e tomar determinância nesse cenário; será que a história oficial de hoje é a história da versão dos guerrilheiros? Hoje já temos ruas, praças e avenidas com nomes de ex-guerrilheiros, mas ainda não em grande número. A Instituição-Universidade também é um local da "minoria guerrilheira", em que muitos ex-guerrilheiros são professores, orientam teses e dissertações sobre o tema, denunciando e expressando outro regime de verdades e fatos históricos que entra em disputa com a "História Oficial". Fato que não surpreende, pois os movimentos guerrilheiros eram compostos em grande parte de intelectuais e estudantes ligados à Universidade (Ridenti, 1993). Mas além dessa relação direta com ex-guerrilheiros, a cada dia mais pesquisadores das Ciências Humanas escrevem dissertações de mestrado, teses de doutorado e artigos sobre o tema, mais próximos da ótica da esquerda política, como Ansara (2008), Arantes (2008), Bauer (2007), Faria (2005), Freire (2007), Hur (2009), entre outros.

Então, em nosso campo de pesquisa constata-se a existência do conflito das memórias. Nosso cenário é de embate, guerra, e não há um consenso sobre os fatos. Portanto, corrobora-se a afirmação de Vázquez (2001), de que a construção da memória interessa mais ao presente e ao futuro do que ao passado; o passado se atualiza e se constrói com sua potência no presente e como processo fundamental para a geração do futuro.

\section{As Teses do Jamil revisitadas pelo olhar do presente}

Para discutir o processo de reconstrução da memória da guerrilha, citaremos partes da entrevista que realizamos com Jamil no ano de 2008 para nossa tese de doutorado, em que foi solicitado que falasse sobre seu passado na luta armada e sobre suas teses militaristas. Realizamos uma entrevista semidiretiva e procedemos por análise do conteúdo (Bardin, 1977; Vázquez, 1997). Analisamos a entrevista através do que Vázquez (1997) denomina de análise de conteúdo categorial temático. Primeiro, opera-se a partir de um trabalho de descodificação, em que se fragmenta o texto transcrito em unidades de registro semânticas. 
Em seguida, agrupam-se as unidades de registro por analogia, constituindo-se temáticas variadas. Dentre os diversos conjuntos temáticos, buscamos selecionar as unidades relevantes para trabalhar o problema de nossa pesquisa. Desse modo, na entrevista de Jamil buscamos agrupar as unidades de registro de seu discurso relacionadas à temática da luta armada, mais especificamente sobre sua (re)leitura sobre as Teses do Jamil. Portanto, neste artigo agrupamos as unidades de registro relacionadas a essa temática, em que, a partir de um exercício dedutivo, refletimos sobre como sua memória da luta armada é reconstruída.

Jamil escreveu um conjunto de textos conhecidos como as Teses do Jamil em 1969. Suas teses foram um referencial teórico e político decisivo para a cisão da Vanguarda Armada Revolucionária - Palmares (VARPalmares), organização da qual a presidenta Dilma Rousseff fez parte, dando ressurgimento à nova VPR. A Vanguarda Popular Revolucionária foi uma das maiores organizações da guerrilha armada brasileira e organizou uma série de ações armadas, como o famoso roubo do cofre do ex-governador paulista Adhemar de Barros, resultando na quantia de aproximadamente 2.500.000,00 de dólares (Solnik, 2011); os sequestros do cônsul do Japão (Vieira, 2008) e dos embaixadores da Alemanha e da Suíça (Sirkis, 1980), com o fim de libertar presos políticos que estavam sendo torturados; o "justiçamento" (execução) do capitão norte-americano Charles Chandler; muitas "expropriações" (assaltos) a bancos e assim por diante. Dentre muitos militantes, participaram da VPR o "Capitão da Guerrilha" Carlos Lamarca e sua companheira, a psicóloga Iara Iavelberg (Patarra, 1993). Vale citar que na VPR, como em outras organizações guerrilheiras latino-americanas, como as FARC (Forças Armadas Revolucionárias da Colômbia), havia uma tensão entre o segmento militarista, derivado dos grupos militares brizolistas, o MNR, que defendia a primazia das ações armadas, e o segmento massista, derivado em parte da Polop, que defendia as ações de conscientização política das massas.

O documento "A Vanguarda Armada e as massas na primeira fase da revolução", texto central das Teses do Jamil, foi republicado na coletânea de Reis Filho e Sá (2006). Consultamos esse documento para conhecer qual era o discurso defendido por Jamil em 1969 para realizar uma comparação com seu discurso do presente. Em síntese, nas Teses do Jamil discute-se o lugar prioritário que a estratégia armada deve ter sobre as ações de trabalho com as massas para a ação revolucionária e luta contra a ditadura militar. Em sua "tática global" supõe a utilização de três dispositivos: a propaganda armada, a guerrilha tática e a coluna guerrilheira estratégica. Para Jamil, "não se trata de fazer as organizações armadas participarem numa insurreição de massas, e sim fazer as massas participarem da guerra revolucionária" (Jamil, 1969, citado por Reis Filho \& Sá, 2006, p. 313), portanto, das massas se armarem. No decorrer do texto notamos a existência de certa prudência ao discutir o ingresso de participantes na luta armada, mas está explícita a primazia do fator militar sobre o fator político de trabalho com as massas e os coletivos populares.

Os ex-guerrilheiros e historiadores Jacob Gorender (1998) e João Quartim de Moraes (1989), ao discutirem as Teses do Jamil, também atribuem ao material um forte caráter militarista. Gorender (1998) considera que Jamil, em suas teses, "estava especialmente apto a dar forma textual ao militarismo extremado, isento de conciliações ecléticas" (p.149), ou seja, dava ênfase às ações armadas das organizações de guerrilha sem conciliar com outros tipos de mobilização, por exemplo, as ações de trabalho com as massas, de conscientização popular. Moraes, também ex-militante da VPR, atribui-lhe intenso militarismo e considera que desprezava a ação de luta das massas:

Um dos apologistas deste ponto de vista, que um ano mais tarde far-se-ia conhecer pelo cognome de Jamil, sustentava ardorosamente, com o apoio de Onofre Pinto - o chefe da VPR até 1969 — que os métodos da luta política de massas, inclusive a imprensa clandestina, eram velharias superadas da "esquerda tradicional". (Moraes, 1989, p. 10)

O ex-guerrilheiro Celso Lungaretti (2004), ao citar o "racha" da VAR-Palmares e o consequente surgimento da "nova VPR", em que teve papel de protagonista, também refere-se ao caráter militarista das Teses do Jamil, que justificaram teoricamente a divisão da Organização, pois considerava-se que a VAR-Palmares estava assumindo um caminho menos militarizado e com ênfase maior de trabalho com as massas. Desse modo, as Teses do Jamil forneceram justificativa teórica e política para retomar os princípios militaristas frente aos massistas, gerando assim o "racha" da organização.

Entretanto, quando perguntamos a Jamil sobre o caráter militarista de suas antigas teses, ele não reafirmou tal perspectiva, e sim releu de outra forma suas próprias ações. Ressalta-se que os números que aparecem entre parênteses referem-se às linhas da entrevista em que se localiza a citação:

O que me preocupava na época era um tipo de confusão que sugeria que a gente armasse o movimento estudantil. O movimento estudantil, a sua legitimidade, o grande número na rua desarmado era 
como uma grande bandeira do povo contra as armas. Você pôr revólver na mão de gente do movimento estudantil é uma baba para os militares. E não é nem um desafio militar, absolutamente ridiculo. Dai a ideia de que as armas fossem utilizadas de maneira extremamente seletiva, desde alimentada em termos financeiros, até como defender diversas ações de propaganda política e coisas do gênero. Mas, enquanto não houvesse um espaço territorialmente limitado, defendido, você dizer armar as massas para fazer guerra popular é uma piada, tinha que ter um senso do ridículo porque não pega. As armas, as poucas armas que a gente tinha não representavam uma ameaça ao país. Representaria uma ameaça para o movimento de massas ao ser utilizado irresponsavelmente. (Jamil, 382-393).

Nesse trecho, Jamil, na sua reconstrução do passado, ao invés de fazer apologia à estratégia armada, como poderia ser esperado pelo pesquisador devido às suas antigas teses, faz a sua crítica. Na sua releitura das teses, defende que movimentos de massa, como o estudantil, não deveriam se armar, pois não se consolidariam como um desafio contra as Forças Armadas. Faz questão de diferenciar quais segmentos sociais da guerrilha deveriam se armar e que deveria haver uma seletividade para o processo de utilização de armas, pois o uso de armas pelos movimentos de massa seria uma irresponsabilidade. Em nossa análise constatamos que tal preocupação já estava presente nas suas teses de 1969, como por exemplo nos trechos: "nosso maior problema não é o de encontrar quadros, mas de formá-los e criar as estruturas para dar-lhes condições de trabalho eficaz" (Jamil, 1969, citado por Reis Filho \& Sá, 2006, p. 302); e "dar receitas de bombas à população, por exemplo, pode levar os setores mais avançados (os que possivelmente atenderiam aos apelos) a uma série de ações suicidas ou inoportunas politicamente" (Jamil, 1969, citado por Reis Filho \& Sá, 2006, p. 305). Entretanto, tais fragmentos selecionados não expressam a tônica principal do texto, que foi interpretado no seu período histórico, pelos historiadores citados e por nós, como apologia à estratégia militarista. Contudo, em sua releitura presente, têm mais importância no seu discurso, que se refere à reconstrução de sua memória, tais atividades de prevenção que as militaristas de ataque. Jamil aumenta ainda mais sua crítica ao afirmar que a estratégia armada guerrilheira não representava ameaça alguma às Forças Armadas. Consideramos que tal análise, expressa pelo seu posicionamento discursivo no presente (Vázquez, 2001), foi realizada após a derrota das guerrilhas urbanas contra o Estado da ditadura e pelo distinto papel social que ocupa. Compreendemos que o que está expresso nas Teses do Jamil vai em direção contrária à afirmação do presente, pois se acreditava no poder político das armas, sendo elas uma saída legítima contra a opressão da ditadura militar. Interpretamos então que a sua memória, através da lente intencional do presente, reconstruiu os fatos de seu passado como uma justificação para seu posicionamento político presente, bastante distinto das interpretações dos historiadores acima citados. Desse modo, consideramos que a reconstrução da memória depende de determinado contexto em que se está inserido; "portanto, pode-se entender o conteúdo das autobiografias e memórias não apenas como o fruto de uma experiência pessoal no passado, senão como o fruto de um determinado consenso social sobre este passado" (Rovira \& Vázquez, 2004, p. 144, tradução nossa). Dessa forma, não é o presente que se distorce para dar sentido a um passado imutável, mas sim o passado que se transforma para justificar o posicionamento presente (Vázquez, 2001). Jamil prossegue:

Esse documento circulou bastante no Brasil para justificar que quando você quer sobreviver de maneira clandestina, não é sair nas ruas e se envolver em confusão mobilizando um monte de gente. Mas se proteger em células, como foi organizado na Argélia, como foi organizado na África do Sul, porque grande parte da contestação armada não pode ficar dando sopa, não adianta rezar, o mundo não vai te proteger. E principalmente num regime que não tinha nenhum problema de pegar o familiar de alguém e ir torturando até descobrir alguém que pudesse dar um contato. Muitíssima gente foi torturada simplesmente para verificar se sabia de alguma coisa. (407-414)

Novamente, ao invés de expressar o caráter agressivo da luta armada, seleciona mais o caráter preventivo, de defesa, de se proteger em células, pequenos agrupamentos, tal como a experiência guerrilheira de outros países. Em sua releitura do passado está presente a ideia de defender-se da intensa violência de Estado desenvolvida pela ditadura militar, que utilizava como instrumento a tortura para obter informações. Entretanto, na análise de suas antigas teses, tal postura de recuo não é claramente perceptível, e sim mais uma postura de ação para a revolução. Como exemplo, citamos mais um trecho das Teses do Jamil: "Nossa guerra é uma guerra popular. É também uma guerra do povo, no sentido de que supõe uma participação ativa das massas dentro da revolução. O problema fundamental é, pois, o seguinte: como organizar a participação do povo na luta?" (Jamil, 1969, citado por Reis Filho \& Sá, 2006, p. 311).

Jamil, mesmo tendo escrito documentos que defendiam o militarismo, atualmente não exalta a experiência da luta armada; muito pelo contrário, critica-a em muitos pontos, mas também não a 
compreende como uma experiência equivocada. Em toda a entrevista fez um movimento de não romantizar e heroicizar a guerrilha armada, afastando a sua experiência de ações de violência:

Você tem que ver que esse negócio de luta armada não é cinema americano; ou seja, não é que você anda por ai dando tiros. Eu participei dois anos, dezesseis horas por dia dessa luta armada, andava armado e para felicidade minha nunca dei um tiro. A gente era muito bem organizado, fazia ações bem montadas. Raríssimas ocasiões houve casos de violência a outras pessoas... (Jamil, 327-331).

Consideramos que nesse trecho ele busca desmistificar a figura do guerrilheiro agressivo, pois ele próprio afirma que sequer foi agente de ação armada violenta. E também seleciona as recordações da organização que a VPR tinha em suas ações, a qual coordenava operações bem montadas. Jamil selecionou e intensificou o que havia de positividade e pouca violência nas ações revolucionárias, pois no próprio seio da VPR há muitos ex-guerrilheiros que fazem intensa autocrítica de ações desenroladas; como exemplo, o justiçamento do Chandler - até hoje não se tem certeza se era ou não espião da CIA - Central Intelligence Agency; as bombas colocadas na Praça 14 bis (em São Paulo) e no jornal o Estado de São Paulo, entre outras.

Então não há essa 'sair na luta armada'. É um processo. Quando você olha que nós tínhamos mais de dez mil pessoas presas em determinado momento, na época, por razões políticas, dez mil pessoas que estão colocando a vida na mesa para mudar as coisas no país; isso é muito. É uma parte da população, legitimamente, que tenta se proteger. Era muita gente. Sobretudo toda a intelectualidade que tinha consciência do que estava ocorrendo, com as entidades politicas do Brasil. Muitas mulheres na guerrilha. Não é fácil saber o que era ser presa como mulher. (Jamil, 336-342)

Nesse momento, Jamil justifica a adesão à luta armada novamente pelo contexto político de violência em que se vivia. O Estado militar havia prendido milhares de pessoas por motivos políticos, então a luta armada poderia ser vista como uma forma de se defender de tal ação repressiva estatal. E, no seu discurso, a luta armada ganhava ainda mais legitimidade devido à grande participação de pessoas e da intelectualidade brasileira politizada, que colocavam suas vidas em risco em prol da democratização do país. Jamil busca justificar sua participação na luta armada partindo de um cenário de injustiça e extrema opressão, ou seja, não por ser um subversivo ou um terrorista violento, mas sim pelo anseio da transformação social.
Consideramos que tal releitura efetuada por Jamil é resultante de uma ressignificação que sua memória, agenciada a partir do presente, faz sobre os fatos passados, focalizando mais o que diz respeito à sua posição social atual, em que a mirada presente molda, reconstrói e modula o passado (Vázquez, 2001) com o intuito de justificar a ação militarista não pelo ataque, mas sim pela defesa em relação à violência do Estado militar e pela luta contra a ditadura. Então, Jamil constrói os fatos passados moldando-os de acordo com sua posição enunciativa do presente, denotando assim a plasticidade da memória (Vázquez, 2001). O seu posicionamento discursivo enquanto professor universitário e economista molda sua memória e imaginário, em que constrói outras versões do passado, outras explicações que são distintas das interpretações que lhe atribuem e possivelmente da qual ele atribuiria há quarenta anos atrás. Recordemos a afirmação citada de Vázquez (2001): tanto o presente como o passado são processos em contínua construção, e é a memória que traz continuidade às distintas temporalidades. Como se compreende o caráter performativo, pragmático, dessas construções, a memória não produz apenas passado, mas também presente e futuro, a partir dos distintos lugares e das distintas posições de enunciação que se ocupa. Enfim, a memória é criação e ação social e, nesse caso, constitui-se uma nova versão de um fenômeno passado, pois está alicerçada pela distinta configuração do presente (Vázquez, 2001). Ou seja, as teses sobre o militarismo não são mais expressão da adoção de uma prática política radical na luta armada e sim pela defesa e prudência nas táticas armadas das organizações guerrilheiras contra a violência do Estado da ditadura.

\section{Considerações finais}

Com este ensaio buscamos mostrar como os caminhos da memória são muito mais fluidos e ramificados, ao invés de assumirem uma linearidade e uma única versão identitária. Há distintas versões sobre as memórias da ditadura militar, o que pode ser facilmente constatado na literatura e relatos de exparticipantes da guerrilha e de ex-militares.

A partir do referencial teórico adotado, das Teses do Jamil e da entrevista realizada com o exguerrilheiro no presente visamos a apresentar como a construção da memória aparece como produção do novo e está agenciada pelas lentes do presente, adotando assim uma plasticidade contingente ao lugar social que se ocupa na atualidade. A memória de forma alguma fica presa ou está restrita ao passado e é dotada de efeitos pragmáticos, pois, articulada à linguagem, 
produz versões sobre o passado e o presente, sendo considerada assim uma ação social (Vázquez, 2001).

Jamil não reconstrói seu passado de forma idêntica ao que passou; faz uma releitura bastante diferenciada de suas antigas teses. Notamos uma grande atenuação referente aos aspectos militaristas da luta armada; suas teses hoje não normatizam uma prática de ataque, mas sim práticas de defesa e prudência. A sua memória aparece extremamente seletiva e interessada, construindo, escolhendo e intensificando as passagens que convergem mais com seu posicionamento político presente numa conjuntura marcada pela democracia e distante dos conflitos políticos armados. Hipotetizamos que Jamil pretende ser reconhecido pelas posições políticas que apresenta hoje, e não pelas antigas; por isso que entendemos que suas teses passaram por tal transformação em sua reatualização. Vale ressaltar que em nenhum momento de sua entrevista houve uma negação ou arrependimento na participação na luta armada, mas sim uma reconfiguração na leitura do passado amparada pelo presente.

Consideramos que os relatos que a Comissão da Verdade coletará também passarão por tais processos. A reconstrução das memórias presentes nos discursos, seja de ex-guerrilheiros, seja de agentes da repressão, não será a restituição idêntica do passado, mas sim a produção de versões alicerçadas e norteadas pelo presente e o que se quer e se imagina do futuro. Serão discursos resultantes de uma memória transformada e em constante produção, implicadas na construção de uma História e de práticas sociais. Sustenta-se que tal plasticidade da memória faz com que a reconstrução do passado seja multifacetada, o que impossibilita a constituição de um consenso único do que foi esse passado, ou a produção de uma memória consensual. Mas caberá aos integrantes da comissão "orquestrar" também esse processo, expressando, selecionando e articulando os distintos regimes de enunciados. Em alguns casos, não apenas coletar um discurso pronto e elaborado, mas trazer um espaço de abertura à escuta daqueles que sofreram a violência do Estado, cujas memórias muitas vezes ainda precisam ser elaboradas.

\section{Agradecimento}

$\mathrm{O}$ autor agradece ao $\mathrm{CNPq}$ e à CAPES pelo financiamento da pesquisa.

\section{Referências}

Ansara, S. (2008). Memória política, repressão e ditadura no Brasil. Curitiba: Juruá.
Arantes, M. A. A. C. (2008). Dor e desamparo: filhos e pais, 40 anos depois. Psicologia clínica, 20(2), 75-87. Acesso em 16 de agosto, 2009, em http://www.scielo.br/pdf/pc/v20n2/ a06v20n2.pdf

Bardin, L. (1977). Análise de conteúdo. Lisboa: Edições 70.

Bauer, C. S. (2007). O departamento de ordem política e social do Rio Grande do Sul (DOPS/RS): terrorismo de estado e ação de polícia política durante a ditadura civilmilitar brasileira. Ágora, 5, 1-31. Acesso em 16 de julho, 2009, em http://www.ufes.br/ppghis/agora/Documentos/ Revista 5 PDFs/Caroline $\% 20$ Silveira $\% 20$ Bauer $\% 20-\% 20$ PDF\%5B1\%5D.pdf

Betto, F. (1982). Batismo de sangue. São Paulo: Círculo do Livro.

Bosi, E. (2003). O tempo vivo da memória: Ensaios de Psicologia Social. São Paulo: Ateliê Editorial.

Caldas, A. (2004). Tirando o capuz ( $4^{\mathrm{a}}$ ed.). Rio de Janeiro: Garamond. (Original publicado em 1981)

Castoriadis, C. (1982). A instituição imaginária da Sociedade. Rio de Janeiro: Paz e Terra.

Certeau, M. (1994). A invenção do cotidiano: Artes de fazer. Petrópolis, RJ: Vozes.

Coelho, M. F. P. (2007). José Genoino: escolhas políticas. São Paulo: Centauro.

Deleuze, G. \& Guattari, F. (1996). Mil Platôs: Capitalismo e Esquizofrenia (Vol. 4). São Paulo: 34.

Dobles, I. (2009). Memorias del dolor: consideraciones de las comisiones de la verdad en America Latina. San Jose: Arlekín.

Faria, C. (2005). Revolucionários, bandidos e marginais: presos politicos e comuns sob a ditadura militar. Dissertação de Mestrado, Programa de História da Universidade Federal Fluminense, Niterói, RJ. Acesso em 29 de março, 2009, em http://www.historia.uff.br/stricto/teses/Dissert-2005 MACHADO_Catia_Conceicao_Faria-S.pdf

Fernandes Jr., O. (2004). O baú do guerrilheiro: memórias da luta armada no Brasil. Rio de Janeiro: Record.

Editorial. (2009, 17 de fevereiro). Limites a Chávez. Folha de São Paulo, p. 2.

Foucault, M. (1999). Em defesa da sociedade: curso dado no Collège de France (1975-1976). São Paulo: Martins Fontes.

Freire, C. P. (2007). As marcas da tortura engendrada pela ditadura militar brasileira. Dissertação de Mestrado, Programa de pós-graduação de Serviço Social, Universidade Federal do Rio de Janeiro. Acesso em 13 de agosto, 2009, em http://www.ess.ufrj.br/dissertacoes_2007/camila-pimentel. pdf

Gabeira, F. (1979). O que é isso, companheiro? Rio de Janeiro: Codecri.

Gaspari, E. (2002). A ditadura envergonhada. São Paulo: Cia das Letras.

Gorender, J. (1998). Combate nas trevas (5 $5^{\mathrm{a}}$ ed. rev. ampl. atual.). São Paulo: Ática.

Guerra, C. (2012). Memórias de uma guerra suja. Cláudio Guerra em depoimento a Marcelo Netto e Rogério Medeiros. Rio de Janeiro: Topbooks.

Halbwachs, M. (2004). A memória coletiva. São Paulo: Centauro.

Hur, D. U. (2009). Discursos do trânsito da Guerrilha ao Estado Neoliberal: Estratopolítica, Tecnopolítica e Nomadopolitica. Tese de Doutorado, Programa de Psicologia Social, Instituto de Psicologia, Universidade de São Paulo, São Paulo, SP. Acesso em 15 de março, 2013, 
em http://www.teses.usp.br/teses/disponiveis/47/47134/ tde-27112009-103453/pt-br.php

Huyssen, A. (2002). En busca del futuro perdido. Cultura y memoria en tiempos de globalización. México: FCE.

Jelin, E. (2002). Los trabajos de la memoria. Madrid: Siglo XXI.

José, E. \& Miranda, O. (1980). Lamarca, o capitão da guerrilha. São Paulo: Global Editora.

José, E. (1997). Carlos Marighella - O inimigo número 1 da ditadura militar. São Paulo: Sol e Chuva.

Laque, J. R. (2010). Pedro e os lobos. São Paulo: Ava Editorial.

Lungaretti, C. (2004). Náufrago da Utopia. São Paulo: Geração Editorial.

Martins Filho, J. R. (2003). A guerra da memória: a ditadura militar nos depoimentos de militantes e militares. Varia História, Belo Horizonte, 28, 178-201.

Merleau-Ponty, M. (1991). Signos. São Paulo: Martins Fontes.

Moraes, J. Q. (1989). A mobilização democrática e o desencadeamento da luta armada no Brasil em 1968: notas historiográficas e observações críticas. Tempo Social, 1(2). Acesso em 29 de março, 2009, em http://www.fflch.usp.br/ sociologia/temposocial_2/pdf/vol01n2/a\%20mobilizacao.pdf

Patarra, J. L. (1993). Iara: reportagem biográfica (4ª ed.). Rio de Janeiro: Rosa dos Tempos.

Paz, C. E. (1996). Viagem à luta armada: memórias romanceadas. Rio de Janeiro: Civilização Brasileira.

Paz, C. E. (1997). Nas trilhas da ALN: memórias romanceadas. Rio de Janeiro: Bertrand.

Pimenta, E. \& Teixeira, E. (2009). Virgílio Gomes da Silva: de retirante a guerrilheiro. São Paulo: Plena Editorial.

Polari, A. (1982). Em busca do tesouro. Rio de Janeiro: Codecri.

Projeto Orvil. (1987). Acesso em 29 de março, 2009, em http:// www.averdadesufocada.com/images/orvil/orvil_completo. pdf

Reis Filho, D. A. (1990). A Revolução faltou ao encontro: os comunistas no Brasil. São Paulo: Brasiliense.

Reis Filho, D. A. \& Sá, J. F. (Orgs.). (2006). Imagens da revolução: documentos políticos das organizações clandestinas de esquerda dos anos 1961-1971 (2ª ed.). São Paulo: Expressão Popular.

Ridenti, M. (1993). O fantasma da Revolução Brasileira. São Paulo: UNESP.

Rovira, M. \& Vázquez, F. (2004). Les autobiografies i memòries de la Transició com a política de la memòria. In M. Rovira \& F. Vázquez (Coords.), Polítiques de la memòria: la transició a Catalunya (pp. 137-173). Barcelona: Pòrtic.

Sandoval, S.A.M. (2001). The Crisis of the Brazilian Labor Movement and Workers Political Consciousness. Psicologia Política, 1(1), 173-195.

Sarlo, B. (2005). Tiempo pasado. Cultura de la memoria y giro subjetivo. Una discusión. Buenos Aires: Siglo XXI.

Sirkis, A. (1980). Os carbonários: memórias da guerrilha perdida. São Paulo: Global.
Solnik, A. (2011). O cofre do Adhemar: a iniciação política de Dilma Roussef e outros segredos da luta armada. Rio de Janeiro: Sextante.

Tapajós, R. (1977). Em câmera lenta. São Paulo: Alfa-omega.

Tavares, F. (1999). Memórias do esquecimento. São Paulo: Globo.

Thompson, P. (1992). A voz do passado: História Oral. São Paulo: Paz e Terra.

Ustra, C. A. (2003). Rompendo o silêncio. Acesso em 22 de março, 2009, em http://www.averdadesufocada.com/images/ rompendo o silencio/rompendosilencio.pdf

Ustra, C. A. (2006). A verdade sufocada: a história que a esquerda não quer que o Brasil conheça. Brasília: Editora Ser.

Vázquez, F. (1997). El dispositiu d'anàlisi de dades: l'Anàlisi de contingut temàtic/categorial (Investigació $i$ Coneixement Psicosocial). Acesso em 7 de fevereiro, 2009, em http:// psicologiasocial.uab.es/campus/mod/resource/view. phpinpopup $=$ true $\& \mathrm{id}=6507$

Vázquez, F. (2001). La memoria como acción social. Relaciones, significados e imaginario. Barcelona: Paidós.

Vianna, M. (2003). Uma tempestade como a sua memória: a história de Lia, Maria do Carmo Brito. Rio de Janeiro: Record.

Vieira, L. (2008). A busca: memórias da resistência. São Paulo: Hucitec.

Recebido em: 28/09/2012

Revisão em: 27/03/2013

Aceite em: 01/06/2013

Domenico Uhng Hur é Professor Adjunto da Universidade Federal de Goiás. Psicólogo, mestre e doutor em Psicologia Social pelo Instituto de Psicologia da Universidade de São Paulo, com estágio doutoral na Universitat Autònoma de Barcelona/Catalunya. Membro do CRISE - núcleo de estudos e pesquisas Crítica, Insurgência, Subjetividade e Emancipação. Endereço: Faculdade de Educação. Rua 235, sn - Setor Universitário .Goiânia/GO, Brasil. CEP 74605-050. Email: domenicoh@usp.br

\section{Como citar:}

Hur, D. U. (2013). Memórias da guerrilha: construção e transformação. Psicologia \& Sociedade, 25(2), 311-320. 